\title{
SEQUÊNCIA DIDÁTICA PARA VALIDAR UM MODELO CIENTÍFICO APROXIMANDO OS ESPAÇOS DE EDUCAÇÃO FORMAL DOS NÃO FORMAIS
}

\author{
Leonardo Polese Alves ${ }^{1}$, Eduardo Augusto Moscon Oliveira ${ }^{2}$ \\ Maria Auxiliadora Vilela Paiva ${ }^{3}$ \\ Programa de Pós-graduação em Educação em Ciências e Matemática \\ Instituto Federal do Espírito Santo - Campus Vitória \\ Avenida Vitória, 1729 - Jucutuquara, Vitória, Espírito Santo. CEP 29040780.
}

\section{RESUMO}

O objetivo desse artigo foi apresentar uma sequência didática que promovesse educação científica na educação profissional e que aproximasse a educação formal dos espaços não formais de educação. 0 artigo faz uma breve discussão sobre sequência didática, apresentando momentos pedagógicos, e finalmente faz considerações sobre alfabetização científica. Essa sequência didática foi desenvolvida em turmas do primeiro período do curso técnico de Geoprocessamento do Ensino Médio do Instituto Federal do Espírito Santo. Os resultados dessa estudo demonstraram que a partir da articulação da educação profissional com a educação científica, foi possível valorizar o ensino da técnica e dos conteúdos procedimentais em sintonia com os conteúdos conceituais e atitudinais.

Palavras-chave: ensino de ciências e matemática, ensino de topografia, modelos científicos, alfabetização científica.

\section{ABSTRACT}

The aim of this paper was to present a didactic sequence that promotes science education in vocational education and close the formal spaces for non-formal education. This article is a brief discussion of instructional sequence, presenting pedagogical moments, and finally makes considerations about scientific literacy. This didactic sequence was developed in the first class period of the GIS technician course at the Federal Institute School of Espírito Santo - Brazil. The results of this study demonstrated that the articulation of vocational education with science education, it was possible to enhance the teaching of technical and procedural contents consistent with the contents conceptual and attitudinal.

Keywords: science and mathematics education. topography education. scientific models. scientific literacy.

\footnotetext{
1 Professor do curso Técnico em Geoprocessamento do Ifes. Engenheiro civil. Mestre em Educação em Ciências e Matemática do Instituto Federal do Espírito Santo. E-mail: leonardopolese@yahoo.com.br

2 Professor de Ensino de História do Departamento de Educação Política e Sociedade. Centro de Educação da UFES. Licenciado e Bacharel em História, D.Ed.; Docente do Programa de Pós-graduação em Educação em Ciências e Matemática do Ifes. E-mail: eduardomoscon@hotmail.com

3 Professora Visitante de Educação Matemática, D.Sc.; Docente do Programa de Pós-graduação em Educação em Ciências e Matemática do Ifes. E-mail: vilelapaiva@gmail.com
}

Revista Eletrônica Debates em Educação Científica e Tecnológica, ISSN: 2236-2150 - V. 2, N. 02, p. 81 - 93, Dezembro, 2012 


\section{INTRODUÇÃO}

A ciência é conjunto de conhecimentos da humanidade socialmente desenvolvidos e/ou adquiridos, historicamente acumulados, dotados de universalidade e objetividade que permitem sua transmissão, e que foram organizados, hierarquizados e sistematizados em princípios, leis, teorias, modelos etc e estruturados com métodos e linguagens próprias. Essa é uma definição genérica de ciência encontrada em dicionários como Ferreira (2009). Mas de modo filosófico, a definição de ciência é a de conhecimento que possua, em qualquer forma ou medida, uma garantia da própria validade: garantia absoluta de validade e sendo como conhecimento, o grau máximo da certeza, em um conceito mais tradicional; e garantia sem pretensões de absoluto, num conceito moderno (ABBAGNANO, 2007).

Enquanto o conhecimento de mundo é completo, intuitivo, infalível, assimétrico e certo, o conhecimento científico é parcial, falível, falseável, contingente (nos contextos espacial e temporal), incerto. Os opostos da ciência são a opinião, caracterizada pela falta de garantia acerca de sua validade e o dogma, caracterizado pela infalibilidade. A educação em ciências evita o dogma e incentiva a argumentação e o debate de idéias. Segundo Driver (1999, p. 32), "os objetos da ciência não são fenômenos da natureza, mas construções desenvolvidas pela comunidade científica para interpretar a natureza". Por isso, o saber científico é simbólico e socialmente negociado "Não devemos pensar a ciência como pronta, acabada, completamente despojada, como uma nova e dogmática religião, com o 'deus saber' imperando [...]. A marca da ciência de nossos dias é a incerteza" (CHASSOT, 2003, p. 98). Mas, esse dogmatismo está presente na educação escolar e pode ser creditado às origens religiosas da universidade e da escola. Superar esse dogmatismo é uma das necessidades do ensino de ciências.

Considerando que a ciência é uma linguagem desenvolvida pela humanidade para explicar o mundo natural, "entender a ciência nos facilita, também, contribuir para controlar e prever as transformações que ocorrem na natureza". E "assim, ser alfabetizado cientificamente é saber ler a linguagem em que está escrita a natureza" (CHASSOT, 2003, p. 91). É considerado um analfabeto científico o sujeito incapaz de fazer a leitura do universo ou parte dele.

Mesmo em domínios relativamente simples da ciência, os conceitos utilizados para descrever e modelar esse domínio não são revelados de maneira óbvia pela leitura do livro da natureza. Ao contrário, esses conceitos são construções que foram inventadas e impostas sobre os fenômenos para interpretá-los e explicá- 
los, muitas vezes como resultado de grandes esforços intelectuais (DRIVER, 1999, p. 32).

Por exemplo, os esforços intelectuais de Galileu Galilei na explicação do movimento de queda livre dos corpos. Durante anos, ele realizou experimentos e medidas com objetos em queda, representando a aceleração em função das mudanças de velocidade do objeto numa dada distância. Depois, Galileu começou a pensar em termos de mudanças de velocidade num dado intervalo de tempo. Então, a aceleração constante dos corpos em queda livre se mostrou evidente.

Depois que esse conhecimento foi construído e acordado dentro da comunidade científica, torna-se parte da forma não problemática de ver as situações.

Como resultado, o mundo simbólico da ciência é hoje povoado por entidades como átomos, elétrons, íons, campos e fluxos, genes e cromossomos; ele é organizado por idéias como a da evolução e inclui procedimentos de medida e experimentos. Essas entidades ontológicas e conceitos organizadores, assim como a epistemologia e as práticas das ciências a eles relacionadas, dificilmente serão descobertas por indivíduos através de suas próprias observações do mundo natural. O conhecimento científico, como conhecimento público, é construído e comunicado através da cultura e das instituições sociais da ciência (DRIVER, 1999, p. 32).

A história e filosofia das ciências têm considerado o conhecimento, que emerge da atividade dentro da comunidade científica, como relativista e resultante de processos sociais. Assim, é difícil saber se esse conhecimento é uma representação verdadeira do mundo natural. Esse relativismo das ciências sugere que o conhecimento científico é limitado pela própria estrutura do mundo e que o progresso científico tem base empírica, mesmo sendo socialmente construído e validado.

Isso significa que a aprendizagem das ciências envolve ser iniciado nas idéias e práticas da comunidade científica e tornar essas idéias e práticas significativas no nível individual do aluno. Então, "o papel do professor de ciências [...] é o de atuar como mediador entre o conhecimento científico e os aprendizes, ajudando-os a conferir sentido pessoal à maneira como as asserções do conhecimento são geradas e validadas" (DRIVER, 1999, p. 33). 
O objetivo do artigo foi apresentar uma sequência didática que favoreça a alfabetização científica utilizando a história dos modelos científicos de Sistema Solar, o modelo atual cientificamente aceito para explicar o Sistema Solar e um modelo concreto de Sistema Solar existente num espaço não-formal de educação, e propondo a validação desse modelo de Sistema Solar implantado nesse espaço não-formal pelos alunos do curso técnico de Geoprocessamento com a utilização de conhecimentos de Ciências, Matemática e Topografia.

\section{PROCEDIMENTOS METODOLÓGICOS}

Alguns autores definiram o termo e escreveram sobre o tema 'sequência didática'. Recuperando uma dessas definições, sequência didática é

um conjunto de atividades ordenadas, estruturadas e articuladas para a realização de certos objetivos educacionais, que têm um princípio e um fim conhecidos tanto pelos professores como pelos alunos. Através da sequência didática é possível analisar as diferentes formas de intervenção e avaliar a pertinência de cada uma delas (ZABALA, 1998, p. 18).

O objetivo principal de uma sequência didática é otimizar o processo ensino-aprendizagem para o aluno. 0 desempenho significativo a ser alcançado com sua utilização está relacionado há pelo menos quatro fatores: os aspectos do conteúdo, da aprendizagem, da atenção à diversidade e da sequência e tipologia dos conteúdos. Zabala (1998) recomenda que as sequências didáticas envolvam os três tipos de conteúdos: conceituais, procedimentais e atitudinais.

Na diversidade educacional esses três conteúdos estão interligados de forma que caminham juntos com o objetivo comum de compreensão de significados. Na elaboração e compreensão de conceitos que é uma das características de conteúdos conceituais é importante que os alunos entendam não apenas o conceito em si, mas como articulá-lo em diversas situações e também para construção de novas ideias. Neste sentido a aprendizagem não precisa ser considerada como finalizada, mas pronta para ampliar conhecimentos de forma que seja significativa. Para aprender um conceito ou princípio é necessário entender o significado deste por meio de um processo de elaboração e construção pessoal deste conceito a ser compreendido. Atividades propícias para o entendimento de certo conceito são aquelas que desafiam o aluno a pensar. 
Os conteúdos procedimentais se referem ao conjunto de habilidades necessárias por meio de técnicas e regras para se alcançar um determinado fim ou objetivo. Por exemplo, a utilização de um equipamento para realizar uma mensuração topográfica. Para aprender procedimentos, os alunos precisam fazer e processar por si próprios todas as ações que alcancem o objetivo proposto. Em atividades que exigem procedimentos, a reflexão é necessária para compreensão dos procedimentos e relacionamentos desses com outros conhecimentos.

O ponto de partida para realizar procedimentos são as ações reais. Desta forma os alunos só aprendem a realizar as ações e constituir os procedimentos cabíveis realizando-os por si próprios. Outro ponto a ser destacado é que deve haver reflexão sobre a atividade realizada para que exista consciência desta e com isso possa melhorar sua atuação. 0 ideal seria que houvesse aplicação das ações em contextos diferentes para articular diversas estratégias de acordo com cada circunstância.

Os conteúdos atitudinais estão agrupados em valores, atitudes e normas. Os valores são princípios que as pessoas emitem num parecer sobre determinadas condutas. As atitudes são as tendências que as pessoas assumem para manter uma conduta considerada correta. Estes conteúdos envolvem afetividade e motivação. E neste âmbito se encaixam os valores humanos como ética, solidariedade, respeito, responsabilidade e participação.

A sequência didática (SD) foi proposta no contexto de um projeto de pesquisa desenvolvido pelo autor desse artigo no Mestrado Profissional em Educação em Ciências e Matemática do Programa de Pós Graduação EDUCIMAT do Instituto Federal do Espírito Santo (Ifes). 0 referido projeto pesquisa a interface do ensino de Ciências e Matemática da educação básica com o ensino de Topografia da educação profissional no Ifes.

A partir dessas bases teóricas e desse contexto de pesquisa foi desenvolvida a proposta de sequência didática que será apresentada a seguir tem o modelo científico para o Sistema Solar como tema central do trabalho pedagógico proposto. Essa SD foi planejada para ser desenvolvida em dez aulas pelos alunos do primeiro período do curso técnico de Geoprocessamento do Ifes em Vitória, na segunda metade do semestre acadêmico pela disciplina de Topografia Prática, mas poderia envolver outras disciplinas desse curso técnico 
de Geoprocessamento, como Matemática, Informática, Geociências, Desenho Técnico e Desenho Assistido por Computador.

Como a SD está sendo proposta para um curso de nível médio da educação profissional, envolve os característicos conteúdos procedimentais característicos dessa educação, mas envolve também os conteúdos conceituais e atitudinais. Os conteúdos procedimentais desenvolvidos serão mensuração, cálculos e desenhos topográficos planimétricos. Os conteúdos conceituais envolvidos serão planimetria (topografia), geometria, escalas, modelos e astronomia do sistema solar. Os conteúdos atitudinais a serem desenvolvidos são pesquisa, organização, trabalho em equipe, e tomada de decisão pela validação ou não de um modelo científico.

O objetivo geral dessa SD é discutir modelo científico (limites, simplificações, representatividade, validação e outros aspectos). E objetivos específicos são:

1) Atualizar os conhecimentos científicos sobre Sistema Solar.

2) Relacionar os conhecimentos científicos sobre o Sistema Solar (unidades astronômicas, modelos e representações) com conhecimentos técnicos (medições topográficas e escalas).

3) Comparar o modelo de Sistema Solar científico como o do Praça da Ciência.

4) Discutir a representatividade do modelo de Sistema Solar da Praça da Ciência.

5) Validar ou não o modelo de Sistema Solar da Praça da Ciência.

6) Utilizar a história da ciência para definir modelos (ou paradigmas), paradigmas dominante e emergente, e rupturas paradigmáticas.

7) Aproximar a educação formal dos espaços não formais de educação.

8) Utilizar esse espaço educativo não formal para praticar Topografia e estudar Astronomia.

9) Conhecer e utilizar os outros equipamentos/experimentos dessa Praça da Ciência. 


\section{RESULTADOS E DISCUSSÃO}

A sequência didática proposta ainda não foi aplicada e é constituída de quinze momentos pedagógicos (M1 ao M15) distribuídos ao longo de dez aulas. Dependo do professor e da turma, a sequência poderá ser desenvolvida em nove ou em onze aulas, diminuindo ou aumentando o tempo dedicado aos momentos M8, M11 e M12.

A primeira aula envolverá dois momentos pedagógicos na própria escola: (M1) o professor apresentará o tema da sequência didática 'o modelo científico-geométrico para o Sistema Solar' e solicitará que os alunos externem seus conhecimentos sobre o Sistema Solar; (M2) o professor exibirá o vídeo 'Jornada no Sistema Solar' de Igor Borgo e Marta F. Barroso do LIMCUFRJ como introdução e motivação para o desenvolvimento dessa SD.

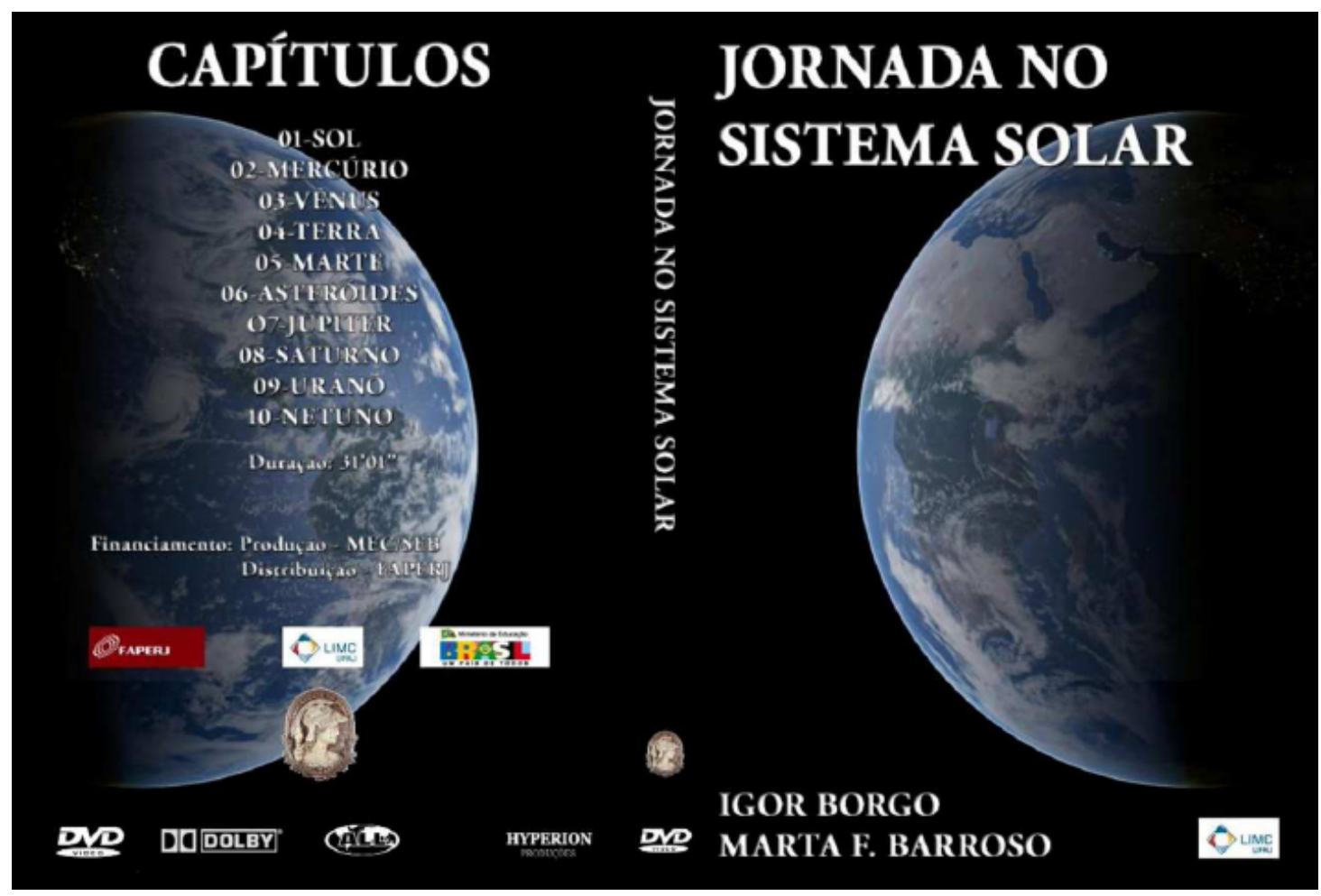

FIGURA 1. Fac símile da capa do DVD Jornada no Sistema Solar (fonte: Revista Brasileira de Ensino Física [online]. http://www.scielo.br/pdf/rbef/v32n2/v32n2a13.pdf). 
O desenvolvimento dessa SD demandará recursos específicos durante alguns momentos pedagógicos. No M2 serão utilizados: computador ou DVD player, projetor multimídia, e o DVD 'Jornada no Sistema Solar’ de Igor Borgo e Marta F. Barroso do LIMC-UFRJ (Figura 1). Apesar do DVD ser enviado gratuitamente quando solicitado pelo email marta@if.ufrj.br, a dificuldade de aquisição é resolvida com o uso de dez vídeos do youtube que compõem os capítulos do DVD.

As segunda e terceira aulas também acontecerão na escola em dois momentos: (M3) o professor exibirá o capítulo 1 ('O que há lá fora?') do documentário 'A História da Ciência' da BBC; (M4) o professor comentará as mudanças de modelos científicos que representaram o Sistema Solar ao longo da história da ciência mostradas nesse documentário e induzirá uma discussão sobre paradigmas dominante versus emergente e mudança de paradigma.

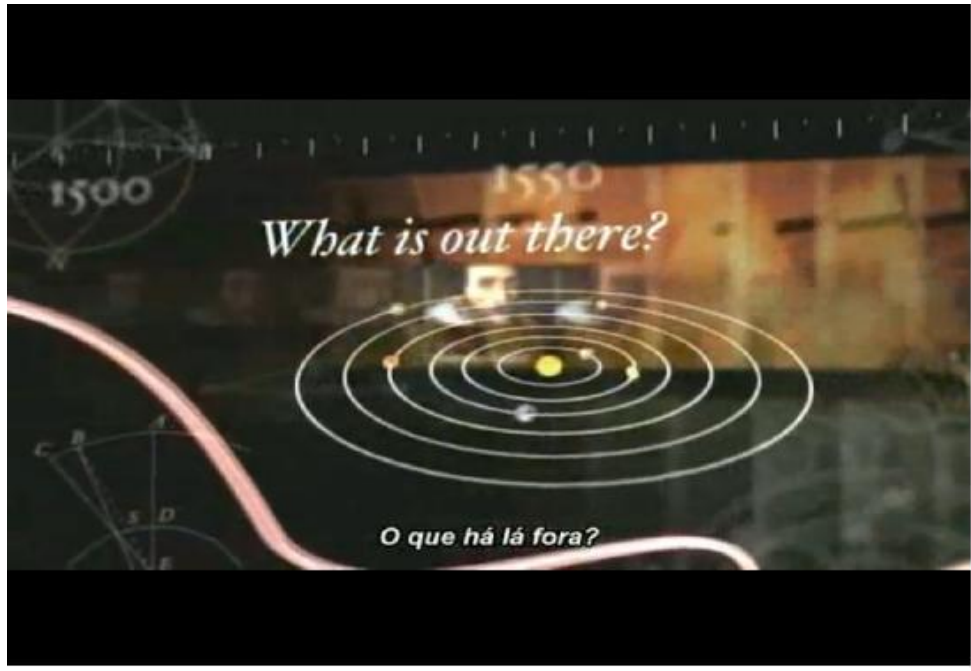

FIGURA 2. Imagem do episódio ‘O que há lá fora?' de 'A Historia da Ciência' (fonte: blog Sr. Curiosidades em srcuriosidades.blogspot.com.br/2011/12/serie-bbc-historia-da-ciencia-titulo.html).

No M3 serão utilizados computador, projetor multimídia e link com acesso à internet para ver os vídeos do youtube.com 'BBC - 1-6 - A Historia da Ciência - 0 que há lá fora?':

a) a parte 1 (inicial) em http://www.youtube.com/watch?v=lEmJUpGCSfw

b) a parte 2 em http://www.youtube.com/watch?v=QYq-fjsMTDY

c) a parte 3 em http://www.youtube.com/watch?v=J21_ou4WpYA 
d) a parte 4 em http://www.youtube.com/watch?v=gdNIkSJTjpg

e) a parte 5 em http://www.youtube.com/watch?v=UyvJEosExOQ

f) a parte 6 (final) em http://www.youtube.com/watch?v=hFn3CB59zWw

Um dos objetivos dessa SD é aproximar a educação formal dos espaços não formais de educação. Para isso a etapa de atividade campo será realizada na 'Unidade Educacional Praça da Ciência' da da Prefeitura Municipal de Vitória (ES). Na "Praça da Ciência, as pessoas podem se divertir vendo a aplicação de princípios físicos e astronômicos do dia a dia. São 11 instrumentos que estão dispostos ao ar livre, os quais o público pode experimentar recebendo as explicações dos monitores. O local é apropriado para despertar o interesse, sobretudo das crianças, pela ciência".

(disponível em <http://www.vitoria.es.gov.br/seme.php?pagina=pracadaciencia> acessado em $13 / 5 / 12)$

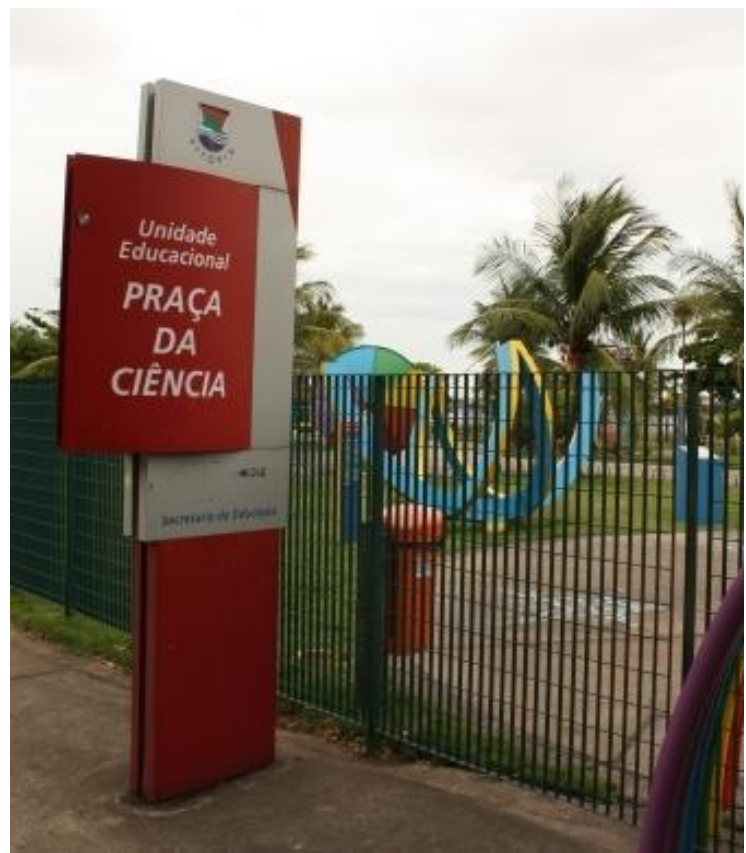

FIGURA 3. Foto placa ao lado da entrada da Praça da Ciência (Fonte: blog Ciência à Bessa em http://scienceblogs.com.br/bessa/2009/12/programa_em_vitria_es_praa_da/) 
A Praça da Ciência (Figura 3) é muito conhecida pela população de Vitória (ES) e da sua região metropolitana. Esta proposta de SD utilizará, em especial, o equipamento "Sistema Solar em escala: (que) reproduz o sistema solar ao longo da praça, com dimensões proporcionais à realidade. Assim, pode-se ter noção do tamanho dos planetas, das distâncias entre eles e de suas órbitas em torno do Sol e também compreender os movimentos de rotação e translação". (idem)

Após a etapa de motivação inicial com a apresentação dos vídeos, acontecerá a etapa de problematização, na qual o professor incentivará os alunos a utilizar os conhecimentos técnicos de Topografia para resolverem uma 'lenda científica urbana' que circula entre alguns professores, técnicos, arquitetos e engenheiros da região metropolitana de Vitória: o modelo de 'Sistema Solar em escala' existente nessa Praça da Ciência está errado, pois tem alguns planetas representados em posições planimétricas erradas, em outras palavras, algumas distâncias Sol-planetas estão erradas. Apesar do círculo restrito de circulação dessa 'lenda científica urbana', o entendimento dela e da possibilidade de erro nas posições dos planetas pelos alunos é plenamente viável.

Assim a quarta aula será dedicada a apenas um momento pedagógico: (M5) o professor fará a problematização apresentando a referida 'lenda' e irá propor que a turma, apoiada na Astronomia do Sistema Solar, Geometria e Topografia, verifique se o referido modelo de 'Sistema Solar em escala' da Praça da Ciência está planimetricamente representado de modo correto ou é válido? No final da aula, o professor solicitará uma pesquisa sobre o modelo científico atual do Sistema Solar

Na quinta aula será desenvolvido o sexto momento pedagógico: (M6) os alunos apresentarão o resultado da pesquisa solicitada no momento pedagógico anterior sobre o modelo cientificamente aceito para explicar o Sistema Solar. O professor e os alunos sistematizarão esses conhecimentos advindos dessa pesquisa. Se os alunos não relatarem, o professor apresentará as unidades para medidas de distâncias astronômicas. 0 professor também deverá listar, além dos conhecimentos sobre Sistema Solar, os conteúdos já estudados pelos alunos e que serão mobilizados nesse empreendimento: Matemática (escalas, projeções, trigonometria, polígonos) e Topografia (poligonais, irradiações, planimétrica, erros). 
As sexta, sétima e oitava aulas serão desenvolvidas no espaço não formal de educação e envolverão quatro momentos pedagógicos: (M7) o professor e a turma serão levados de ônibus do Ifes-Vitória para a Praça da Ciência, onde conhecerão o equipamento (experimento) do Sistema Solar em escala; (M8) os alunos farão as medidas topográficas (ângulos e distâncias) necessárias para verificar se esse modelo está certo ou errado; (M9) os alunos conhecerão e utilizarão os outros equipamentos da Praça da Ciência (relógio de sol, espelho de som, elevador de mão, ...); e (M10) o professor e a turma serão levados de ônibus da Praça da Ciência para o Ifes-Vitória, e nessa viagem de volta o professor incentivará os alunos a refletirem sobre como eles verificarão, a partir das medidas feitas, se o modelo está corretamente representado ou não.

Os recursos necessários para os momento M7 a M10 são: ônibus para transportar a turma N18 na ida do Ifes-Vitória até a Praça da Ciência e na volta; equipamentos topográficos (teodolito, trenas, balizas, mira estadimétrica, bússola e calculadora); e agendamento prévio com a Praça da Ciência.

As nona e décima aulas concluirão a sequência didática com cinco momentos na própria escola: (M11) com os dados obtidos nas medidas topográficas, os alunos farão cálculos e desenhos para reproduzir o modelo do Sistema Solar da Praça da Ciência; (M12) os alunos compararão esse modelo da Praça da Ciência com o modelo científico atual do Sistema Solar; (M13) o professor e os alunos discutirão as diferenças entre os modelos (científico e Praça da Ciência) e os limites para validar o modelo do Sistema Solar em escala da Praça da Ciência; (M14) os alunos decidirão se o modelo do Sistema Solar da Praça da Ciência está representado corretamente em escala de distâncias (declarando a falsidade da lenda) ou está errado (declarando a pertinência dessa lenda científica urbana), em outras palavras, a turma promoverá a validação ou não desse modelo; e (M15) os alunos avaliarão a sequência didática executada e avaliarão também a utilização desse equipamento e do espaço não-formal de educação.

No momento pedagógico M11 serão utilizados: calculadora, mesa com prancheta e régua paralela para desenho técnico, escalímetro, esquadros, compasso, computador. 
A avaliação dos alunos será dividida em duas partes de valores iguais: a primeira refere-se a participação dos alunos na pesquisa, na atividade de campo e nos debates sobre a validação do modelo para avaliar os conteúdos procedimentais e atitudinais; e a segunda refere-se aos cálculos, desenhos e argumentos apresentados na validação do modelo para avaliar os conteúdos conceituais.

\section{CONSIDERAÇÕES FINAIS}

Como a ciência é uma linguagem desenvolvida pela humanidade, ela deve ser considerada mutável e falível. É preciso desconstruir características atribuídas indevidamente à ciência: infalibilidade (crença de que a ciência não falha e na erra) e cientificismo (doutrina que considera os fazeres científicos sempre como benéficos).

Se o conhecimento científico é uma instância privilegiada de relações de poder, então esse conhecimento, patrimônio da humanidade, deve ser socializado. A validação do conhecimento científico é feita pela comunidade científica. Além de ampliar as possibilidades de acesso à ciência, alunos e cidadãos devem compreender como a validação de conhecimentos e modelos científicos é feita.

A alfabetização científica não deve apenas favorecer a leitura do mundo em que vivemos, mas deve mostrar também a necessidade de transformá-lo em um mundo melhor. Se a sociedade financia as pesquisas que se fazem na ciência, então a ciência deve ter compromissos com a sociedade. Ou seja, a sociedade não deve se submeter à ciência, mas ciência é que dever estar a serviço da sociedade. A ciência também deve se ocupar de transformar saber acadêmico em saber escolar e de transformar saber popular em saber escolar.

A alfabetização científica acontece quando o ensino de ciências contribui para a compreensão de conhecimentos, procedimentos e valores que permitam aos cidadãos tomar decisões, perceber tanto as utilidades da ciência e suas aplicações na melhora da qualidade de vida, quanto as limitações e conseqüências negativas de seu desenvolvimento. 


\section{REFERÊNCIAS}

ABBAGNANO, Nicola. Dicionário de Filosofia. 5. ed. São Paulo: Martins Fontes, 2007.

BARROSO, Marta F. e BORGO, Igor. Jornada no Sistema Solar. Revista Brasileira de Ensino de Física, vol.32, n.2, p. 2502-1 - 2502-12, abr-jun 2010.

CHASSOT, Ático. Alfabetização científica: uma possibilidade para a inclusão social. Revista Brasileira de Educação, no 22, p. 89 - 100, Jan/Fev/Mar/Abr 2003.

DRIVER, Rosalind; ASOKO, Hilary; LEACH, John; MORTIMER, Eduardo; SCOTT, Phillip. Construindo conhecimento científico na sala de aula. Química Nova na Escola, no 9, p. 31 40, maio 1999.

FERREIRA, Aurélio B. de Holanda. Novo dicionário Aurélio da língua portuguesa. 4. ed. Curitiba: Positivo, 2009.

ZABALA, Antoni. A prática educativa: como ensinar. Porto Alegre: Artmed, 1998. 